\title{
Platelet Aggregation-Induced by Caco-2 Cells: Regulation by Matrix Metalloproteinase-2 and Adenosine Diphosphate
}

\author{
Carlos Medina, Paul Jurasz, Maria Jose Santos-Martinez, Soon Seog Jeong, \\ Timothy Mitsky, Ridong Chen, and Marek W. Radomski
}

Department of Integrative Biology and Pharmacology and Institute of Molecular Medicine for the Prevention of Human Diseases, University of Texas, Houston, Texas (C.M., P.J., M.J.S.-M., M.W.R.); APT Therapeutics Inc., St. Louis, Missouri (S.S.J., T.M., R.C.); and Gastroenterology Department, Hospital Universitario de Canarias, Tenerife, Spain (C.M.)

Received November 8, 2005; accepted January 18, 2006

\begin{abstract}
Formation of tumor cell-platelet aggregates facilitates hematogenous metastases. However, molecular mechanisms implicated in tumor cell-induced platelet aggregation (TCIPA) in colon cancer are unclear. To investigate mechanisms of TCIPA induced by colon adenocarcinoma cells in vitro, human Caco-2 cells were used to study their interactions with platelets using aggregometry, zymography, phase-contrast microscopy, and flow cytometry. Caco-2-induced platelet aggregation in a concentration-dependent manner. This aggregation resulted in the release of matrix metalloproteinase (MMP)-2, as measured by
\end{abstract}

zymography. In addition, flow cytometry showed a significant up-regulation of activated Gpllb/llla, total Gpllb/IIla, Gplb, and $\mathrm{P}$-selectin receptors on platelets. Inhibition of MMP-2 by phenantroline and degradation of ADP by APT102, respectively, resulted in inhibition of TCIPA. Furthermore, both phenantroline and APT102 significantly down-regulated the surface abundance of platelet receptors. Caco-2 cells aggregate platelets, at least in part, via releasing MMP-2 and ADP. Modulation of MMP-2 and ADP actions could have therapeutic value in colonic cancer.
Colorectal cancer is the fourth most common type of cancer in Western countries and the second leading cause of death from cancer in North America (Gill et al., 2004). Approximately 40 to $50 \%$ of patients who undergo potentially curative surgery finally relapse and die of metastatic disease (Andre et al., 2004). Interestingly, some patients develop thrombotic complications during the course of the disease (Tasi et al., 2004). There is strong evidence that platelets play an important role in the pathophysiology of metastasis (Nash et al., 2002; Gupta and Massague, 2004; Jurasz et al., 2004). In fact, cancer cells have the ability to induce platelet aggregation that confers several advantages to the survival of the tumor cells and its successful metastasis (Jurasz et al., 2004). Moreover, this ability to aggregate platelets correlates with the metastatic potential of tumor cells (Gasic et al.,

This work was supported, in part, by a grant from the Secretaria de Estado de Educacion y Universidades fellowship, cofunded by the European Social Fund (to C.M.), and by Instituto de Salud Carlos III (C03/02), Madrid, Spain C.M. is a postdoctoral fellow of the Spanish Ministry of Education. M.J.S.-M. was supported by grants from Fundacio Catalana Pneumologia, Barcelona; Sociedad Española de Neumologia y Cirugia Toracia, Barcelona; and Societat Catalana de Pneumologia, Barcelona, Spain.

Article, publication date, and citation information can be found at http://jpet.aspetjournals.org.

doi:10.1124/jpet.105.098384.
1968; Radomski et al., 1991). There are diverse mechanisms involved in tumor cell induced-platelet aggregation (TCIPA), where platelets can be activated by cancer cells releasing $\mathrm{ADP}$, thromboxane $\mathrm{A}_{2}$, and matrix metalloproteinase-2 (Jurasz et al., 2001; Alonso-Escolano et al., 2004).

$\mathrm{ADP}$ is stored in platelet-dense granules, and it is a potent proaggregatory agent that can be released during TCIPA induced by fibrosarcoma, breast carcinoma, and neuroblastoma cells (Bastida et al., 1986; Jurasz et al., 2001; AlonsoEscolano et al., 2004). However, the role of ADP in platelet aggregation induced by colon cancer cells is not clear (Scarlett et al., 1987; Grignani and Jamieson, 1988).

Matrix metalloproteinases (MMPs) comprise an ever-growing family of zinc- and calcium-dependent endopeptidases that are capable of degrading most components of the extracellular matrix (Sternlicht and Werb, 2001). MMPs participate in tissue remodeling in diverse physiologic situations, including embryogenesis, wound healing, and angiogenesis (Sternlicht and Werb, 2001). Moreover, overexpression of these enzymes is also implicated in the degradation of basement membrane facilitating tumor invasion. In addition, we have found previously that platelet aggregation may be mediated via the release of MMP-2 from platelets (Sawicki et al., 1997). Interestingly, we have also shown that MMP-2

ABBREVIATIONS: TCIPA, tumor cell-induced platelet aggregation; MMP, matrix metalloproteinase; FITC, fluorescein isothiocyanate; PE, phycoerythrin; TXA $\mathrm{A}_{2}$, thromboxane $\mathrm{A}_{2}$. 
release from platelets and cancer cells is involved in platelet aggregation induced by human fibrosarcoma HT-1080, lung carcinoma A549, and breast adenocarcinoma MCF7 cells (Jurasz et al., 2001; Alonso-Escolano et al., 2004). Although the mechanisms of MMP-mediated stimulation of platelets are not well understood, interactions between MMP-2 and platelet receptors could play an important role (Martinez et al., 2001; Galt et al., 2002).

GPIIb/IIIa is the major platelet surface transmembrane receptor, and it plays an important role in platelet aggregation (Shattil et al., 1998). In addition, platelets contain a pool of this glycoprotein stored in $\alpha$-granules (Wagner et al., 1996). Furthermore, GPIb, the von Willebrand factor-binding subunit of the GPIb/V/IX, mediates mainly platelet adhesion (Andrews and Berndt, 2004). Finally, P-selectin, which is also stored in platelet $\alpha$-granules, mediates platelet-leukocyte aggregation since it is rapidly translocated to the surface upon platelet activation (Andrews and Berndt, 2004).

We have now established an in vitro experimental model of TCIPA induced by Caco- 2 cells. Using this model, we aimed at studying whether intestinal adenocarcinoma cells were able to induce platelet aggregation, molecular mechanisms responsible for the formation of platelet-human intestinal cancer cell aggregates, the abundance of different platelet receptors during TCIPA, and the regulation of Caco-2-induced platelet aggregation and the receptor abundance in the presence of several pharmacologic inhibitors of platelet aggregation.

\section{Materials and Methods}

Reagents. All reagents were purchased from Sigma Chemical Co. (St. Louis, MO) unless otherwise indicated. Collagen was obtained from Chronolog (Havertown, PA). Fluorescein isothiocyanate (FITC)conjugated monoclonal antibody against high-affinity GPIIb/IIIa (PAC-1-FITC) was purchased from Becton Dickinson Biosciences (Mississauga, ON, Canada). $R$-Phycoerythrin (PE)-conjugated monoclonal antibody against human platelet GPIb (CD42b-PE) and allophycocyannin-conjugated monoclonal antibody against human platelet P-selectin (CD62P) were purchased from BD Biosciences (San Jose, CA).

Expression and Purification of Human Apyrase APT102. CD39L3 was cloned from the large-insert human brain cDNA library (CLONTECH, Palo Alto, CA) by polymerase chain reaction using gene-specific primers. A soluble form of CD39L3 (APT101) was generated by removing the $\mathrm{N}$-terminal 44 amino acids and the $\mathrm{C}$-terminal 43 amino acids. To facilitate cloning of APT101 into vectors suitable for expression in mammalian cells, an SmaI restriction site was introduced in-frame with the ATG of APT101. The resulting polymerase chain reaction product was cloned into the SmaI site of pSP72 (Promega, Madison, WI). Two point mutations, R67G and T69R, were introduced into APT101 coding sequence using the quick change site-directed mutagenesis kit (Stratagene, La Jolla, CA). The gene of the mutant, designated APT102, was cloned into expression plasmid vector pSEQTAG2a (Invitrogen, Carlsbad, CA). Expression plasmid was transfected into HEK $293 \mathrm{~T}$ cell line. The recombinant protein of APT102 was secreted from HEK293 cell lines and purified from conditioned medium using anion-exchange chromatography, size-exclusion chromatography, and affinity chromatography.

Cell Culture. Caco-2 cells, a human intestinal adenocarcinoma cell line, were obtained from the American Type Culture Collection (Manassas, VA). Cells were cultured in $75-\mathrm{cm}^{2}$ flasks in a humidified atmosphere containing $5 \% \mathrm{CO}_{2}$ at $37^{\circ} \mathrm{C}$. Cells were grown in minimum essential medium supplemented with pyruvate, sodium bicarbonate, $20 \%$ fetal bovine serum, gentamicin sulfate $(0.05 \mathrm{mg} / \mathrm{ml})$, penicillin $\mathrm{G}(0.06 \mathrm{mg} / \mathrm{ml})$, and streptomycin sulfate $(0.01 \mathrm{mg} / \mathrm{ml})$. The medium was changed every 2 days, and cells were subcultured three times each week. When confluent, cells were detached using EDTA $(7 \mathrm{mM})$ in Dulbecco's phosphate-buffered saline and gentle shaking. EDTA was then washed away with Tyrode's solution; afterward, Caco-2 cells were resuspended in Tyrode's solution and counted.

Preparation of Human Washed Platelets. Blood was collected from healthy volunteers who had not taken any drugs known to affect platelet function for at least 14 days prior to the study. Washed platelet suspensions $\left(2.5 \times 10^{8}\right.$ platelets $\left./ \mathrm{ml}\right)$ were prepared from blood as described previously (Radomski and Moncada, 1983).

Platelet Aggregation. The interactions between platelets and tumor cells were measured by light aggregometry (Radomski et al., 1991; Jurasz et al., 2001; Alonso-Escolano et al., 2004).

In brief, platelet samples $\left(2.5 \times 10^{8} / \mathrm{ml}\right)$ were placed in a wholeblood ionized calcium lumi-aggregometer (Chronolog) and incubated for $2 \mathrm{~min}$ at $37^{\circ} \mathrm{C}$, with stirring at $900 \mathrm{rpm}$, prior to the addition of aggregating agents. For most experiments, collagen at a concentration that resulted in maximal aggregation $(5 \mu \mathrm{g} / \mathrm{ml})$ was used as a control agonist. TCIPA was initiated by the addition of tumor cells $\left(10^{2}-10^{5}\right.$ cell $\left.\mathrm{s} / \mathrm{ml}\right)$, and the reaction was monitored and analyzed by the Aggro-Link data-processing system (Chronolog) for up to $30 \mathrm{~min}$. Platelet aggregation was expressed as the percentage of aggregation at a time when the highest concentration of tumor cells increased the light transmittance by $50 \%$ (Jurasz et al., 2001). To study the involvement of $\mathrm{TXA}_{2}$ and MMP-2-dependent pathways in Caco-2-induced platelet aggregation, platelets were preincubated for $2 \mathrm{~min}$ with inhibitors of these pathways, such as acetylsalicylic acid (aspirin) and $o$-phenanthroline (Jurasz et al., 2001; Alonso-Escolano et al., 2004), and aggregation was induced with $1.5 \times 10^{3}$ cells $/ \mathrm{ml}$. To study the involvement of ADP in TCIPA, a new human apyrase, APT102, was tested with the same number of tumor cells as above.

Sample Preparation for Zymography. In brief, platelets at a concentration of $2.5 \times 10^{8} / \mathrm{ml}$ were placed into the lumi-aggregometer, and tumor cells were added at different concentrations $(1.5 \times$ $10^{3}-10^{5}$ ). The aggregates of platelets and tumor cells were collected after $30 \mathrm{~min}$ of incubation in the aggregometer. The samples were centrifuged at $900 \mathrm{~g}$ at room temperature for $10 \mathrm{~min}$, yielding the pellet and the releasate. The pellets were then homogenized on ice three times (10 s each) using a Vibra Sonic sonicator (Sonics and Materials Inc., Danbury, CT). Both the pellet homogenate and the releasate were stored at $-20^{\circ} \mathrm{C}$ until assayed for the presence of MMP activity by zymography.

Zymography. Gelatin zymography was used to detect the activity of MMP-2 and MMP-9. Zymographic analysis was carried out on aggregates of platelets and tumor cells, as described previously (Jurasz et al., 2001; Alonso-Escolano et al., 2004). In brief, samples were subjected to $10 \%$ SDS-polyacrylamide gel electrophoresis with copolymerized gelatin (0.2\%; Sigma Chemical Co.) incorporated as a substrate for gelatinolytic proteases. After electrophoresis, the gels were washed with $2.5 \%$ Triton X-100 (three times, 20 min each) and then incubated for $48 \mathrm{~h}$ at $37^{\circ} \mathrm{C}$ in enzyme assay buffer $(25 \mathrm{mM}$ Tris $\mathrm{HCl}, 0.9 \% \mathrm{NaCl}, 5 \mathrm{mM} \mathrm{CaCl}_{2}$, and $0.05 \% \mathrm{Na}_{3} \mathrm{~N}, \mathrm{pH}$ 7.5). The conditioned medium of HT-1080 human fibrosarcoma cells (that contains high amounts of proMMP-2, MMP-2, proMMP-9, and MMP-9), was used as control. After 48-h development, gels were fixed and stained in $40 \%$ methanol, $10 \%$ acetic acid, and $0.1 \%(\mathrm{w} / \mathrm{v})$ Coomassie Blue R-250 (Sigma Chemical Co.) for $1 \mathrm{~h}$ and then destained in $4 \%$ methanol with $8 \%$ acetic acid. The gelatinolytic activities were detected as transparent bands against the background of Coomassie Bluestained gelatin. MMP-2 was identified by its mol. wt. when compared with conditioned medium of HT-1080 human fibrosarcoma cells. The intensities of the separate bands were analyzed and quantified using the ChemiDoc XRS System (Bio-Rad, Hercules, CA). The gelatinolytic activity of each band was expressed as arbitrary units of density per milligram of protein.

Microscopy of TCIPA. The structure of platelet-tumor cell aggregates was studied using phase-contrast microscopy (Jurasz et al., 
2001; Alonso-Escolano et al., 2004). In brief, Caco-2 cells $\left(1.5 \times 10^{3}\right.$ cells $/ \mathrm{ml})$ were added to the platelet suspension $\left(2.5 \times 10^{8} / \mathrm{ml}\right)$ in the presence or absence of TCIPA inhibitors phenantroline and APT102, and aggregation was terminated at 50\% maximal aggregation, as determined using the aggregometer. The samples were fixed by adding $2 \%$ paraformaldehyde in Tyrode's solution, $\mathrm{pH} 7.4$, and then incubated for $30 \mathrm{~min}$ at room temperature. Aliquots of each sample were then taken for phase-contrast microscopy examination using an Olympus CKX41 microscope (Olympus America Inc., Melville, NY). Photomicrographs were captured using a digital camera and MicroFire (Olympus America Inc.) software (Jurasz et al., 2001; AlonsoEscolano et al., 2004).

Flow Cytometry. The abundance of GPIIb/IIIa, GPIb, and Pselectin on the surface of platelets during TCIPA was measured by flow cytometry (Jurasz et al., 2001; Radomski et al., 2001; Chung et al., 2002; Alonso-Escolano et al., 2004). Platelets were activated with tumor cells $\left(1.5 \times 10^{3}\right.$ cells $\left./ \mathrm{ml}\right)$ in the presence or absence of aspirin, $o$-phenanthroline, or APT102, which was added 2 min prior to tumor cells. When TCIPA reached 50\% maximal light transmission, the reaction was terminated by 10 -fold dilution with physiologic saline. Resting platelets were used as control. Samples were then incubated in the dark for $5 \mathrm{~min}$ at room temperature in the presence of saturating concentrations $(10 \mu \mathrm{g} / \mathrm{ml})$ of FITC-antiGPIIb/IIIa (CD41FITC), PE-antiGPIb (CD42b-PE), or P-selectin (CD62P-allophycocyannin). The activated GPIIb/IIIa platelet receptors were measured using PAC-1 monoclonal antibody at the same concentration as above. PAC-1 specifically recognizes an epitope on the high-affinity GPIIb/IIIa complex of activated platelets at or near the platelet (Abrams et al., 1990). Following incubation, samples were diluted in FACS Flow fluid and analyzed within 5 min using a Beckman Coulter FC500 dual-laser five-color flow cytometer (Beckman Coulter, Fullerton, CA). Flow cytometry was performed on singlestained platelet samples as described previously (Radomski et al., 2005). The instrument was set up to measure the size (forward scatter), granularity (side scatter), and cell fluorescence. A twodimensional analysis gate based on forward and side scatter was drawn to exclude platelet-tumor cell aggregates and microparticles. Antibody binding was measured by analyzing individual platelets for fluorescence. The mean fluorescence intensity was determined after correction for cell autofluorescence. For each sample, the fluorescence was analyzed using a logarithmic scale. Fluorescence histograms were obtained for 10,000 individual events. Data were analyzed using Cytometer RXP software and expressed as a percentage of control fluorescence in arbitrary units.

Statistics. The data were analyzed using one-way analysis of variance (GraphPad Prism software; GraphPad Software Inc., San Diego, CA). The results are expressed as mean \pm S.E.M. of at least three independent experiments. Tukey-Kramer multiple comparisons test and paired and unpaired Student's $t$ tests were performed where appropriate. Statistical significance was considered when $P<0.05$.

\section{Results}

Caco-2 Cell-Induced Platelet Aggregation. Caco-2 cells were tested for their ability to induce platelet aggregation. When platelets were incubated in the aggregometer for $30 \mathrm{~min}$ at $37^{\circ} \mathrm{C}$ without the addition of tumor cells, no platelet aggregation was detected. However, colon adenocarcinoma cells induced platelet aggregation in a concentrationdependent manner (Fig. 1, A and B). In addition, this aggregation was preceded by a lag phase of several minutes that decreased as the concentration of Caco-2 cells increased (Fig. 1A). Because the concentration of $1.5 \times 10^{3}$ cells $/ \mathrm{ml}$ was sufficient to induce platelet aggregation, all remaining experiments were performed with this amount of cells.
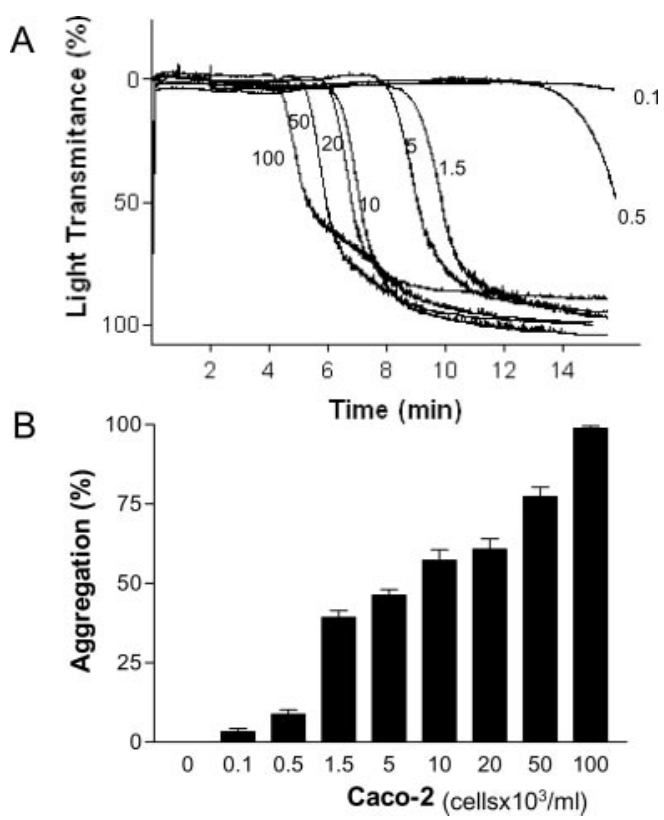

Fig. 1. Induction of platelet aggregation by Caco-2 cells. These tumor cells induced platelet aggregation in a concentration-dependent manner. A, representative traces showing TCIPA at different concentrations of tumor cells $\left(0.1\right.$ to $\times 10^{5}$ cells $\left./ \mathrm{ml}\right)$. B, corresponding concentration-response bar graph expressed as percentage of aggregation.

MMP-2 Activity in Cancer Cell-Platelet Homogenates and Their Releasates. Zymography was conducted to study whether MMP-2 and MMP-9 were involved in Caco2 -induced platelet aggregation. The proMMP-2 was the major gelatinase detected, as shown by the $72-\mathrm{kDa}$ band. $\mathrm{Zy}$ mography showed a significant decrease in the MMP-2 activity in cancer cell-platelet pellets compared with unaggregated platelets $(P<0.0005 ; n=4)$ when Caco-2 cells were added to induce platelet aggregation (from $1.5 \times 10^{3}$ to $10^{5}$ cells/ml) (Fig. 2A). In addition, there was a significant increase in MMP-2 activity in the releasate of aggregated platelets induced by Caco-2 in comparison with unaggregated platelets $(P<0.0001 ; n=4)$, indicating the enzyme release during TCIPA (Fig. 2B). No significant differences were found in MMP-9 activity when Caco-2 cells were added to induce platelet aggregation (data no shown).

Inhibition of Caco-2-Induced Platelet Aggregation. We used selective inhibitors of three TXA 2 , MMPs, and ADP (Sawicki et al., 1997; Jurasz et al., 2001) to characterize the mechanism of Caco-2-induced platelet aggregation. Aspirin $(100 \mu \mathrm{M})$, APT102 $(40-160 \mu \mathrm{g} / \mathrm{ml})$, and $o$-phenanthroline $(500 \mu \mathrm{M})$ were used to inhibit $\mathrm{TXA}_{2^{-}}$, ADP-, and MMP-2mediated pathways of aggregation, respectively. Aspirin did not exert any significant effect on TCIPA (Fig. 3, A and B). However, this concentration of aspirin inhibited collageninduced aggregation by $56 \pm 7 \%(n=4)$ and abolished arachidonic acid-induced $(100 \mu \mathrm{M})$ aggregation $(n=4)$. In contrast to aspirin, phenantroline inhibited Caco-2-induced platelet aggregation, as shown by aggregometry (Fig. 3, A and B) and phase-contrast microscopy (Fig. 4). Interestingly, APT102 also inhibited aggregation induced by Caco-2 in a concentration-dependent manner and prolonged lag phase (Figs. 3, C and D, and 4).

Measurement of Platelet Receptors during Caco-2Induced Aggregation. The interactions of platelets with 

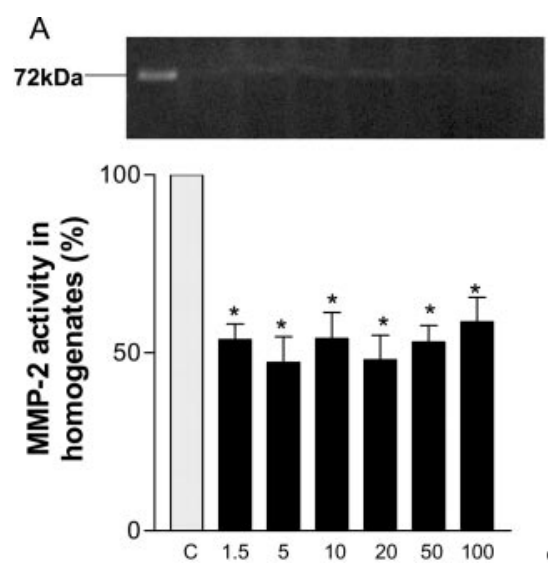

A

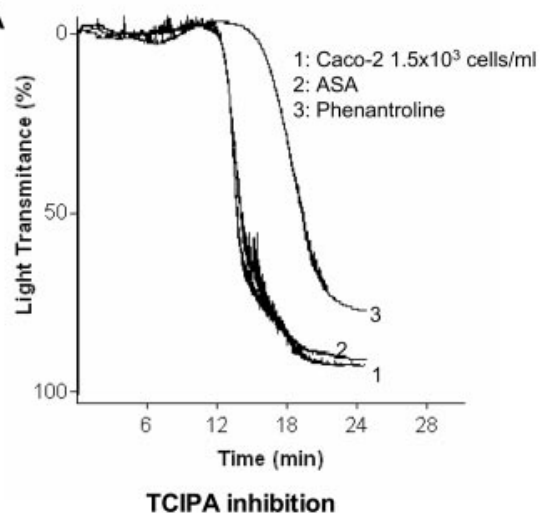

B

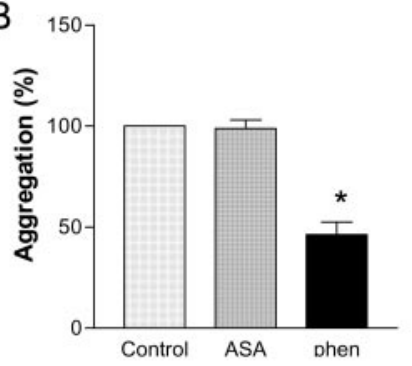

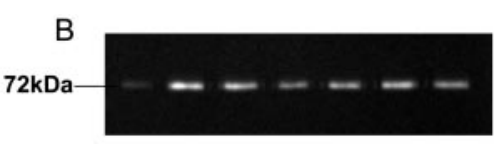

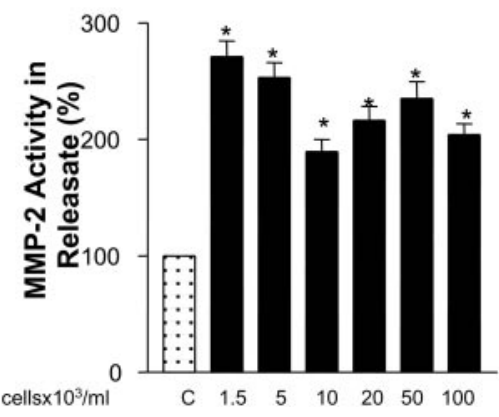

Fig. 2. Zymography of homogenates (A) and releasates (B) of Caco-2 cells and platelets. Unaggregated platelets were considered as controls (open bars). Densitometric analysis showed a significantly decrease in $72-\mathrm{kDa}$ MMP-2 activity in cell-platelet homogenates when tumor cells were added to induce TCIPA (*, $P<0.0005$ versus control), corresponding with a significant increase in MMP-2 activity in the releasates $(*, P<0.0001$ versus control). Insets, zymograms from representative experiments.

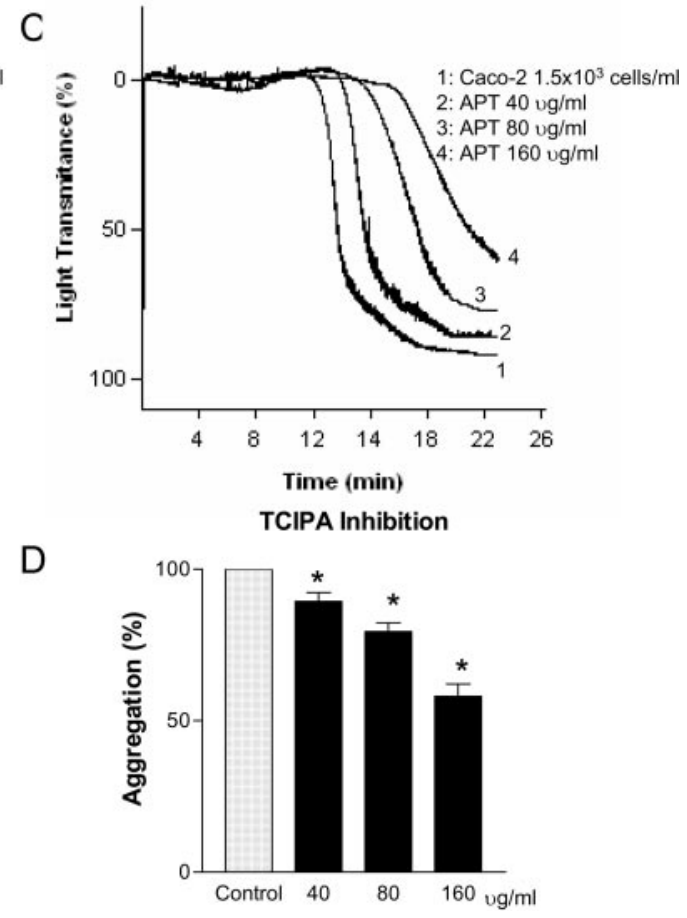

Fig. 3. Inhibition of platelet aggregation induced by Caco-2 with selective inhibitors of the three major pathways of platelet aggregation. A, representative traces showing TCIPA inhibition by phenantroline $(500 \mu \mathrm{M})$ but not aspirin $(100 \mu \mathrm{M})$. B, corresponding bar graphs, expressed as percentage of aggregation. C, representative traces showing TCIPA inhibition by APT102 in a concentration-dependent manner $(40-160 \mu \mathrm{g} / \mathrm{ml})$. D, corresponding bar graphs, expressed as percentage of aggregation $(*, P<0.05$ treatments versus control). tumor cells induced a significant $(P<0.005 ; n=4)$ increase in the number of copies of activated GPIIb/IIIa (PAC-1) on platelets (Fig. 5A). Furthermore, platelet activation with Caco- 2 cells $\left(1.5 \times 10^{3}\right.$ cells $\left./ \mathrm{ml}\right)$ resulted in a significant increase in the number of copies of total GPIIb/IIIa $(P<$ $0.005 ; n=4)$, GPIb $(P<0.01 ; n=4)$, and P-selectin $(P<$ $0.005 ; n=4)$ on platelets in comparison with resting platelets (Fig. 5, B-D).

Effects of Inhibitors on Receptors during Caco-2Induced Platelet Aggregation. Flow cytometry performed on platelets preincubated with aspirin $(100 \mu \mathrm{M})$ and $o$-phenanthroline $(500 \mu \mathrm{M})$ and then activated by Caco-2 cells was analyzed. Phenantroline significantly $(P<0.01$, $n=4$ ) inhibited Caco-2-mediated increase in total GPIIb/ IIIa, activated GPIIb/IIIa, GPIb, and P-selectin (Fig. 6, A-D). In contrast, aspirin failed to prevent the increase in platelet surface abundance of these receptors $(P>0.05, n=4)$ (Fig. 6 , A-D). Because $40 \mu \mathrm{g} / \mathrm{ml}$ APT102 was found to be sufficient to inhibit aggregation induced by Caco- 2 cells, the following flow-cytometry experiments conducted to study the effects of this compound on platelet receptors during TCIPA were per- formed using this concentration of inhibitor. Interestingly, APT102 also significantly inhibited $(P<0.01, n=4)$ upregulation of receptors on the surface of platelets during TCIPA (Fig. 6, A-D).

\section{Discussion}

Platelets have been implicated in tumor metastasis and thrombotic complications of patients with colorectal adenocarcinoma (McCarty et al., 2002; Im et al., 2004). However, the relative contribution of $\mathrm{ADP}, \mathrm{MMP}-2$, and $\mathrm{TXA}_{2}$ to colon cancer-induced platelet aggregation still remains unclear. Therefore, the aim of our investigation was to study the interactions between human intestinal cancer cells and platelets. Furthermore, we studied the expression of major receptors on the platelet surface during TCIPA. In addition, we tested the effects of different pharmacologic compounds on Caco-2-induced platelet aggregation.

First, we used human colon adenocarcinoma cells, Caco-2, to study their interactions with platelets in vitro. We showed that Caco- 2 cells were able to induce platelet aggregation in 


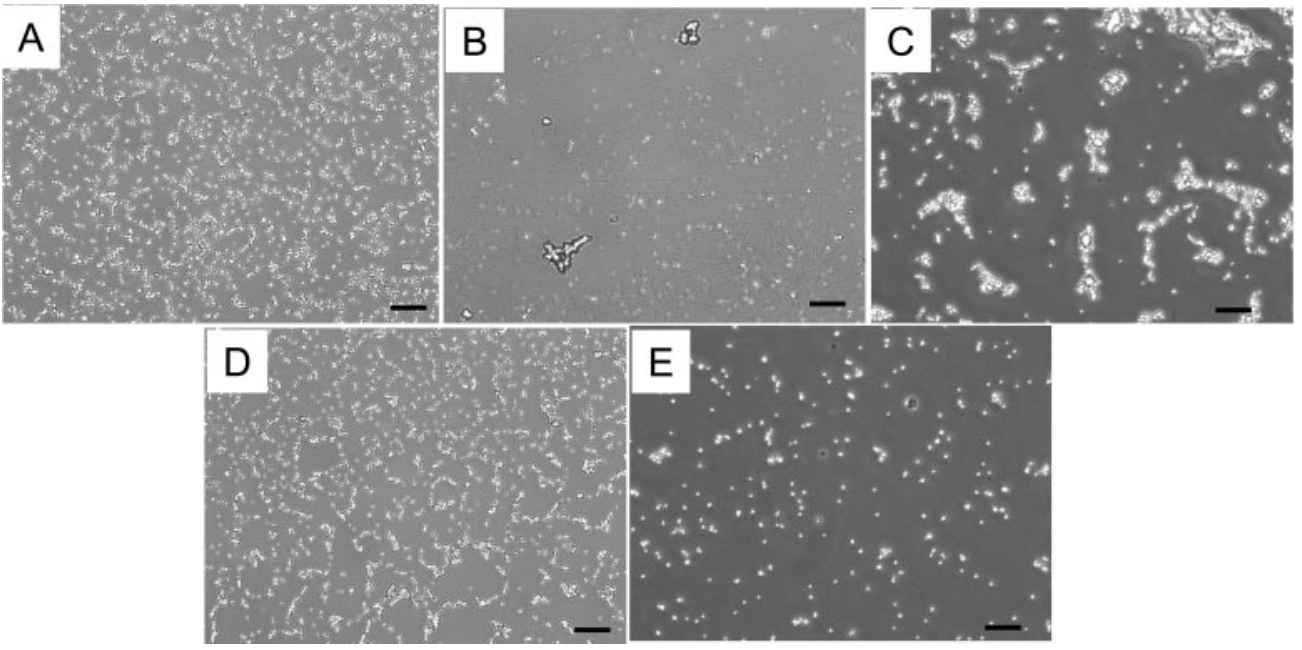

Fig. 4. Phase-contrast microscopy of unaggregated platelets (A), aggregated platelets by collagen used as positive control (B), TCIPA induced by Caco- 2 at $50 \%$ of aggregation with the presence of big platelet aggregates (C), TCIPA induced by Caco-2 in the presence of phenantroline $(500 \mu \mathrm{M})$ (D), and TCIPA in the presence of APT102 $(40 \mu \mathrm{M})$ with less formation of big platelet aggregates than without pharmacological compounds (E). Scale bar, $20 \mu \mathrm{m}$.

a concentration-dependent manner, as evidenced by aggregometry.

Knowing that Caco-2 cells stimulated platelet aggregation, we next studied the molecular mechanisms implicated in this interaction. We have shown previously the requirement for activated MMP-2 to induce the MMP-2-dependent pathway both in agonist and TCIPA induced by HT-1080 and MCF7 breast cancer cells (Jurasz et al., 2001; Alonso-Escolano et al., 2004). In the present study, we have found that MMP-2 is released during platelet aggregation induced by Caco- 2 cells. We have found previously that MMP-9 may inhibit platelet aggregation counteracting the effects of MMP-2 (FernandezPatron et al., 1999). However, Caco-2-induced platelet aggregation did not result in significant release of MMP-9, suggesting that MMP-2 is the dominant gelatinase released during Caco-2-induced platelet aggregation. However, we did not study other MMPs, such as MMP-1, which has been also involved in agonist platelet aggregation (Galt et al., 2002). Therefore, the precise role of this enzyme during TCIPA remains to be elucidated. MMP-2 has been previously in-
A

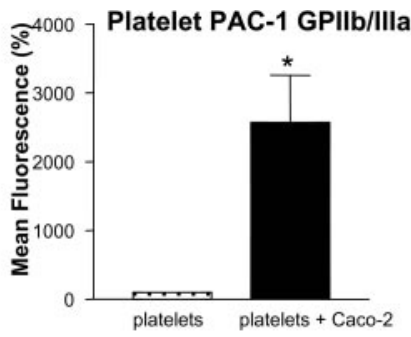

B

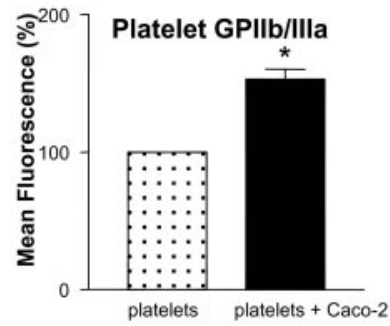

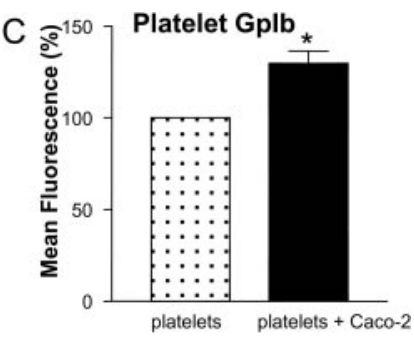

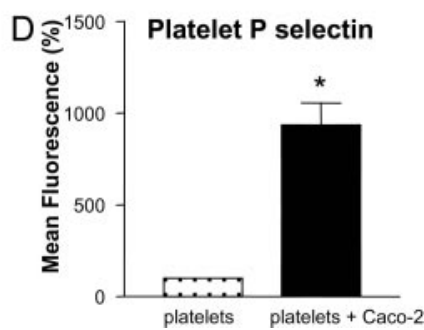

Fig. 5. Flow-cytometry analysis of activated (PAC-1) and nonactivated GPIIb/IIIa, GpIb, and P-selectin on platelets during TCIPA (at 50\% aggregation). Unaggregated platelets in the absence of tumor cells were considered as controls. TCIPA induced by Caco- 2 significantly increased the abundance of all receptors on platelet surface (*, $P<0.01$ versus control). volved in colorectal cancer in humans since this enzyme has been found in regions of tumor invasion (Papadopoulou et al., 2001; Ornstein and Cohn, 2002). In addition, a single-nucleotide polymorphism in the MMP-2 promoter region that increases gene transcriptional activity has been associated with colon cancer development and invasion (Xu et al., 2004).

Numerous studies have suggested that aspirin and other nonsteroidal anti-inflammatory drugs, particularly highly selective COX-2 inhibitors, could be used as chemoprophylactic agents preventing colorectal adenoma and cancer, especially in patients with familiar adenomatous polyposis (Thun et al., 2002). However, aspirin did not reduce TCIPA in our study, suggesting that TXA2-mediated pathway of aggre-
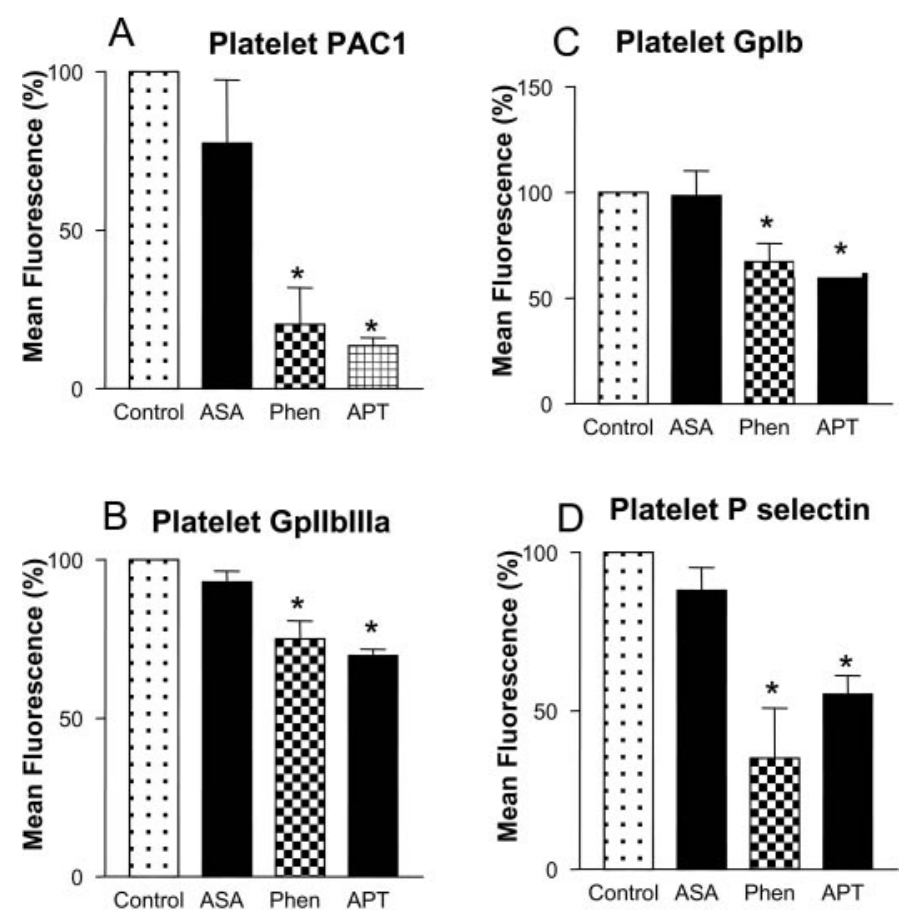

Fig. 6. Flow-cytometry analysis of activated (PAC-1) and nonactivated GPIIb/IIIa, GPIb, and P-selectin on platelets during TCIPA (at 50\% aggregation) in the presence of different inhibitors. Aggregated platelets with Caco-2 cells in the absence of inhibitors were used as controls. Phenantroline and APT102, but not aspirin, significantly reduced the abundance of all receptors on platelet surface $(*, P<0.01$ versus control). 
gation is unlikely to be implicated in Caco-2-induced platelet aggregation.

The role of ADP in colon cancer-induced platelet aggregation is controversial. Some studies have shown that TCIPA induced by colon cell lines is ADP-dependent since TCIPA was partly abolished by potato apyrase (Scarlett et al., 1987). However, other researchers have found that colon carcinomas do not promote platelet aggregation through the production of ADP (Grignani and Jamieson, 1988). Interestingly, during the course of our investigation, human apyrase APT102 was able to attenuate platelet aggregation induced by Caco- 2 cells in a concentration-dependent manner. In humans, apyrases maintain vascular fluidity and modulate inflammation by metabolically deleting extracellular ADP and ATP released by activated platelets (Marcus et al., 2003). APT102 is a human apyrase optimized by protein engineering. This protein exhibited a 4-fold higher ADPase activity than the wild-type enzyme CD39L3 and a well characterized isozyme CD39. The improved enzymatic activity was correlated with significantly higher potency to inhibit and even reverse ADP-induced platelet aggregation (Jeong et al., 2004). Therefore, taken together, MMP-2 and ADP released during the TCIPA seem to be the major pathways of platelet aggregation triggered by Caco- 2 .

Because platelet receptors mediate platelet adhesion and aggregation, we next studied the changes in the abundance of these receptors on platelets induced by human colon adenocarcinoma cells. In our study, we found that Caco- 2 cells increased the number of copies of GPIIb/IIIa (both nonactivated and activated receptors), GPIb, and P-selectin, as measured by flow cytometry. GPIIb/IIIa is constitutively expressed as inactive receptor on the platelet surface, but upon platelet aggregation, this receptor becomes active and binds several protein ligands (Bennett, 2001). GPIb is also constitutively expressed in platelets, and its main role is to attach platelets to the injured part of the vascular wall (Ruggeri, 1999). Both GPIIb/IIIa and GPIb have been implicated in tumor cell-platelet interactions and subsequent tumor metastasis since colon carcinoma cells pretreated with antibodies against platelet GPIb and/or GPIIb/IIIa inhibited their ability to induce platelet aggregation (Grossi et al., 1988). $\mathrm{P}$-selectin is mainly stored in platelet $\alpha$-granules, and upon platelet activation, this receptor is translocated to the platelet surface mediating leukocyte rolling and the formation of platelet-leukocyte aggregates (Andrews and Berndt, 2004). In addition, platelet $\mathrm{P}$-selectin has been involved in colon carcinoma cell tethering and rolling in an in vitro model (McCarty et al., 2000). Furthermore, it has been shown previously that inhibition of $\mathrm{P}$-selectin-mediated cell adhesion of human colon carcinoma by heparin treatment may have a potential therapeutic value (Wei et al., 2004).

Because platelet MMP-2 is translocated to platelet surface membrane during aggregation (Sawicki et al., 1998), we next studied the interaction of this enzyme with the different platelet receptors during TCIPA. We have shown previously that the release of platelet MMP-2 is associated with the activation of GPIIb/IIIa receptor (Martinez et al., 2001); furthermore, human recombinant MMP-2 increased GPIb in platelets adhering to von Willebrand factor (Radomski et al., 2001). Our data showed that the broad-spectrum MMP inhibitor, phenantroline, reduced Caco-2-induced up-regulation of platelet receptors. Therefore, our study suggests that
MMP-2 is crucial for the formation of Caco-2-platelet aggregates via activation of the different receptors on the platelet surface. Interestingly, APT102 also significantly reduced the number of copies of GPIIb/IIIa (both nonactivated and activated receptors), GPIb, and P-selectin on the platelet surface during TCIPA to a similar extent, suggesting that the release of ADP during TCIPA also plays an important role in upregulation of platelet receptors.

In conclusion, our results show that Caco- 2 cells stimulate platelet aggregation through the release of MMP-2 and ADP. The proaggregatory effects of Caco- 2 are associated with an increase of platelet GPIb, GPIIb/IIIa, and P-selectin receptors. Modulation of MMP-2- and ADP-mediated pathways may represent an effective therapeutic approach to prevent or reduce tumor metastasis induced by colon adenocarcinoma.

\section{Acknowledgments}

We thank Anna Radomski for assistance in blood collection and invaluable technical help.

\section{References}

Abrams CS, Ellison N, Budzynski AZ, and Shattil SJ (1990) Direct detection of activated platelets and platelet-derived microparticles in humans. Blood 75:128 138

Alonso-Escolano D, Strongin AY, Chung AW, Deryugina EI, and Radomski MW (2004) Membrane type-1 matrix metalloproteinase stimulates tumour cell-induced platelet aggregation: role of receptor glycoproteins. Br J Pharmacol 141:241-252. Andre T, Boni C, Mounedji-Boudiaf L, Navarro M, Tabernero J, Hickish T, Topham C, Zaninelli M, Clingan P, Bridgewater J, et al. (2004) Oxaliplatin, fluorouracil and leucovorin as adjuvant treatment for colon cancer. N Engl J Med 350:23432351.

Andrews RK and Berndt MC (2004) Platelet physiology and thrombosis. Thromb Res 114:447-453.

Bastida E, Escolar G, Almirall L, and Ordinas A (1986) Platelet activation induced by a human neuroblastoma tumor cell line is reduced by prior administration of ticlopidine. Thromb Haemost 55:333-337.

Bennett JS (2001) Platelet-fibrinogen interactions. Ann NY Acad Sci 936:340-354 Chung AW, Jurasz P, Hollenberg MD, and Radomski MW (2002) Mechanisms of action of proteinase-activated receptor agonists on human platelets. $\mathrm{Br} J$ Pharmacol 135:1123-1132.

Fernandez-Patron C, Martinez-Cuesta MA, Salas E, Sawicki G, Wozniak M, Radomski MW, and Davidge ST (1999) Differential regulation of platelet aggregation by matrix metalloproteinases-9 and -2. Thromb Haemost 82:1730-1735.

Galt SW, Lindemann S, Allen L, Medd DJ, Falk JM, McIntyre TM, Prescott SM, Kraiss LW, Zimmerman GA, and Weyrich AS (2002) Outside-in signals delivered by matrix metalloproteinase-1 regulate platelet function. Circ Res 90:1093-1099.

Gasic GJ, Gasic TB, and Stewart CC (1968) Antimetastatic effects associated with platelet reduction. Proc Natl Acad Sci USA 61:46-52.

Gill S, Loprinzi CL, Sargent DJ, Thome SD, Alberts SR, Haller DG, Benedetti J, Francini G, Shepherd LE, Francois Seitz J, et al. (2004) Pooled analysis of fluorouracil-based adjuvant therapy for stage II and III colon cancer: who benefits and by how much? J Clin Oncol 22:1797-1806.

Grignani G and Jamieson GA (1988) Platelets in tumor metastasis: generation of adenosine diphosphate by tumor cells is specific but unrelated to metastatic potential. Blood 71:844-849.

Grossi IM, Hatfield JS, Fitzgerald LA, Newcombe M, Taylor JD, and Honn KV (1988) Role of tumor cell glycoproteins immunologically related to glycoproteins $\mathrm{Ib}$ and $\mathrm{IIb} / \mathrm{III}$ in tumor cell-platelet and tumor cell-matrix interactions. FASEB $J$ 2:2385-2395.

Gupta GP and Massague J (2004) Platelets and metastasis revisited: a novel fatty link. J Clin Investig 114:1691-1693.

Im JH, Fu W, Wang H, Bhatia SK, Hammer DA, Kowalska MA, and Muschel RJ (2004) Coagulation facilitates tumor cell spreading in the pulmonary vasculature during early metastatic colony formation. Cancer Res 64:8613-8619.

Jeong S, Broekman M, Mitsky T, Chen R, and Marcus AJ (2004) Antithrombotic activity of a novel engineered human apyrase: enzymatic profile, ex vivo and in vivo properties (Abstract). Blood 104:530.

Jurasz P, Alonso-Escolano D, and Radomski MW (2004) Platelet-cancer interactions: mechanisms and pharmacology of tumour cell-induced platelet aggregation. $\mathrm{Br} J$ Pharmacol 143:819-826.

Jurasz P, Sawicki G, Duszyk M, Sawicka J, Miranda C, Mayers I, and Radomski MW (2001) Matrix metalloproteinase 2 in tumor cell-induced platelet aggregation: regulation by nitric oxide. Cancer Res 61:376-382.

Marcus AJ, Broekman MJ, Drosopoulos JHF, Islam N, Pinsky DJ, Sesti C, and Levi R (2003) Metabolic control of excessive extracellular nucleotide accumulation by CD39/ectonucleotidase-1: implications for ischemic vascular diseases. J Pharma col Exp Ther 305:9-16.

Martinez A, Salas E, Radomski A, and Radomski MW (2001) Matrix metalloproteinase-2 in platelet adhesion to fibrinogen: interactions with nitric oxide. Med Sci Monit 7:646-651. 
McCarty OJT, Jadhav S, Burdick MM, Bell WR, and Konstantopoulos K (2002) Fluid shear regulates the kinetics and molecular mechanisms of activation-dependent platelet binding to colon carcinoma cells. Biophys $J$ 83:836-848.

McCarty OJT, Mousa SA, Bray PF, and Konstantopoulos K (2000) Immobilized platelets support human colon carcinoma cell tethering, rolling and firm adhesion under dynamic flow conditions. Blood 96:1789-1797.

Nash G, Turner L, Scully M, and Kakkar A (2002) Platelets and cancer. Lancet Oncol 3:425-430.

Ornstein DL and Cohn KH (2002) Balance between activation and inhibition of matrix metalloproteinase-2 (MMP-2) is altered in colorectal tumors compared to normal colonic epithelium. Dig Dis Sci 47:1821-1830.

Papadopoulou S, Scorilas A, Arnogianaki N, Papapanayiotou B, Tzimogiani A, Agnantis N, and Talieri M (2001) Expression of gelatinase-A (MMP-2) in human colon cancer and normal colon mucosa. Tumour Biol 22:383-389.

Radomski A, Jurasz P, Alonso-Escolano D, Drews M, Morandi M, Malinski T, and Radomski MW (2005) Nanoparticle-induced platelet aggregation and vascular thrombosis. Br J Pharmacol 146:882-893.

Radomski A, Stewart MW, Jurasz P, and Radomski MW (2001) Pharmacological characteristics of solid-phase von Willebrand factor in human platelets. $\mathrm{Br} J$ Pharmacol 134:1013-1020.

Radomski M and Moncada S (1983) An improved method for washing of human platelets with prostacyclin. Thromb Res 30:383-389.

Radomski MW, Jenkins DC, Holmes L, and Moncada S (1991) Human colorectal adenocarcinoma cells: differential nitric oxide synthesis determines their ability to aggregate platelets. Cancer Res 51:6073-6078.

Ruggeri ZM (1999) Structure and function of von Willebrand factor. Thromb Haemost 82:576-584.

Sawicki G, Salas E, Murat J, Miszta-Lane H, and Radomski MW (1997) Release of gelatinase A during platelet activation mediates aggregation. Nature (Lond) $\mathbf{3 8 6}$ 616-619.
Sawicki G, Sanders EJ, Salas E, Wozniak M, Rodrigo J, and Radomski MW (1998) Localization and translocation of MMP-2 during aggregation of human platelets. Thromb Haemost 80:836-839.

Scarlett JD, Thurlow PJ, Connellan JM, and Louis CJ (1987) Plasma-dependent and -independent mechanisms of platelet aggregation induced by human tumour cell lines. Thromb Res 46:715-726.

Shattil SJ, Kashiwagi H, and Pampori N (1998) Integrin signaling: the platelet paradigm. Blood 91:2645-2657.

Sternlicht MD and Werb Z (2001) How matrix metalloproteinases regulate cell behavior. Annu Rev Cell Dev Biol 17:463-516.

Tasi SH, Juan CJ, Dai MS, and Kao WY (2004) Trousseau's syndrome related to adenocarcinoma of the colon and cholangiocarcinoma. Eur J Neurol 11:493-496.

Thun MJ, Henley SJ, and Patrono C (2002) Nonsteroidal anti-inflammatory drugs as anticancer agents: mechanistic, pharmacologic and clinical issues. J Natl Cancer Inst 94:252-266.

Wagner C, Mascelli M, Neblock D, Weisman H, Coller B, and Jordan R (1996) Analysis of GPIIb/IIIa receptor number by quantification of $7 \mathrm{E} 3$ binding to human platelets. Blood 88:907-914

Wei M, Tai G, Gao Y, Li N, Huang B, Zhou Y, Hao S, and Zeng X (2004) Modified heparin inhibits P-selectin-mediated cell adhesion of human colon carcinoma cells to immobilized platelets under dynamic flow conditions. J Biol Chem 279:2920229210.

Xu E, Lai M, Lv B, Xing X, Huang Q, and Xia X (2004) A single nucleotide polymorphism in the matrix metalloproteinase-2 promoter is associated with colorectal cancer. Biochem Biophys Res Commun 324:999-1003.

Address correspondence to: Dr. Marek W. Radomski, School of Pharmacy and Pharmaceutical Sciences, University of Dublin Trinity College, Dublin 2, United Kingdom. E-mail: radomskm@tcd.ie 